\title{
About the Cover Image
}

\author{
Jonathan A. Allan, Chris Haywood, and Frank G. Karioris
}

ลูก

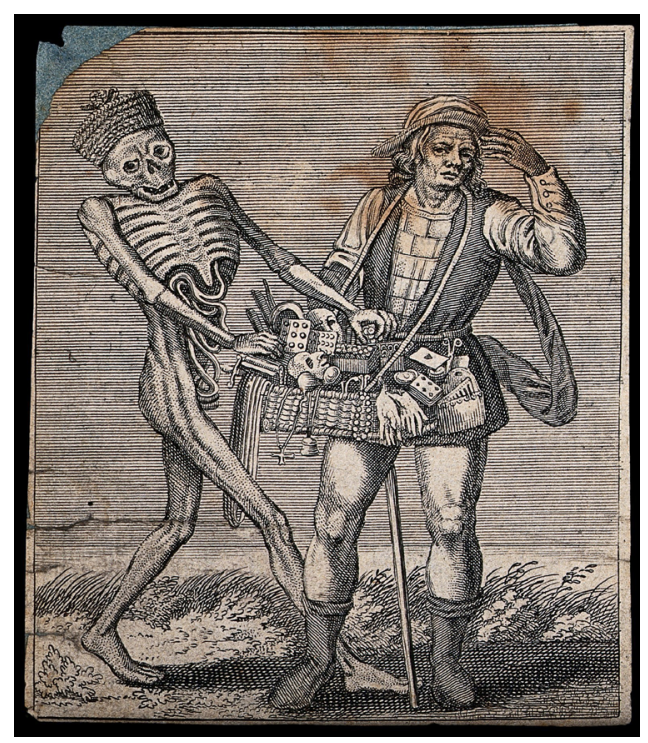

Dance of death: death and the pedlar. Etching attributed to J.-A. Chovin, 1720-1776, after the Basel dance of death.

Credit: Wellcome Collection. Attribution 4.0 International (CC BY 4.0)

As we have stated in Volume 1 Issue 1 and Issue 2, our goal in the Journal of Bodies, Sexualities, and Masculinities is to do things differently. Each of our covers has featured a new image that sheds distinct light onto the topic of the articles and the broader journal as a whole. Throughout our time as a journal we will utilize a variety of archives and collections for our images.

On the cover of this issue is an image taken from the Wellcome Collection. Titled "Dance of death: death and the pedlar", the image shows a skeletal personification of Death picking through a basket of goods. In the basket are included masks, crosses, a deck of cards, swords, and a variety of 
other items. Published in the 18th Century, it is based on, and an interpretation of a piece in Basel on the Dance of Death. It is black and white and a print produced via etching a plate and using this to print the image.

The piece was selected for the cover of this issue to point towards the first year of the pandemic; the hundreds of thousands of people who have lost their lives - many due to inaction, bad policies, or campaigns of misinformation; and to the political violence that the past year has seen. In this, the image builds on the introduction and the nota bene within it. Here, Death is both literal as well as more figurative, representing those in the world who would profit and proffer false narratives.

That the second figure in the image is a salesperson reminds us, again, of the way that "essential workers" have been put in death's way; and the fact that the economy (in its fictitious state often) has been put above and beyond the wellbeing of people. This state of economy over people is not new, it is simply that the pandemic has torn asunder the clothes that have hung to the shoulders of the economy, now revealed as death. 